\title{
Beyond climate envelopes: effects of weather on regional population trends in butterflies
}

\author{
Michiel F. WallisDeVries • Wendy Baxter • \\ Arnold J. H. Van Vliet
}

Received: 23 June 2010 / Accepted: 19 April 2011 / Published online: 18 May 2011

(C) The Author(s) 2011. This article is published with open access at Springerlink.com

\begin{abstract}
Although the effects of climate change on biodiversity are increasingly evident by the shifts in species ranges across taxonomical groups, the underlying mechanisms affecting individual species are still poorly understood. The power of climate envelopes to predict future ranges has been seriously questioned in recent studies. Amongst others, an improved understanding of the effects of current weather on population trends is required. We analysed the relation between butterfly abundance and the weather experienced during the life cycle for successive years using data collected within the framework of the Dutch Butterfly Monitoring Scheme for 40 species over a 15 -year period and corresponding climate data. Both average and extreme temperature and precipitation events were
\end{abstract}

Communicated by Roland Brandl.

Electronic supplementary material The online version of this article (doi:10.1007/s00442-011-2007-z) contains supplementary material, which is available to authorized users.

M. F. WallisDeVries $(\varangle) \cdot$ W. Baxter

De Vlinderstichting/Dutch Butterfly Conservation,

P.O. Box 506, 6700 AM Wageningen, The Netherlands

e-mail: michiel.wallisdevries@ vlinderstichting.nl

M. F. WallisDeVries

Laboratory of Entomology, Wageningen University,

P.O. Box 8031, 6700 EH Wageningen, The Netherlands

W. Baxter · A. J. H. Van Vliet

Environmental Systems Analysis Group, Wageningen University, P.O. Box 47, 6700 AA Wageningen, The Netherlands

Present Address:

W. Baxter

Department of Integrative Biology, University of California

Berkeley, Berkeley, CA 94720, USA identified, and multiple regression was applied to explain annual changes in population indices. Significant weather effects were obtained for 39 species, with the most frequent effects associated with temperature. However, positive density-dependence suggested climatic independent trends in at least 12 species. Validation of the short-term predictions revealed a good potential for climate-based predictions of population trends in 20 species. Nevertheless, data from the warm and dry year of 2003 indicate that negative effects of climatic extremes are generally underestimated for habitat specialists in drought-susceptible habitats, whereas generalists remain unaffected. Further climatic warming is expected to influence the trends of 13 species, leading to an improvement for nine species, but a continued decline in the majority of species. Expectations from climate envelope models overestimate the positive effects of climate change in northwestern Europe. Our results underline the challenge to include population trends in predicting range shifts in response to climate change.

Keywords Climate change - Bioclimatic models . Population trends $\cdot$ Life history $\cdot$ Butterflies

\section{Introduction}

The effects of climate change on biodiversity are increasingly evident by the shifts in species ranges across taxonomical groups, from invertebrates to birds. Documented changes mainly consist of northward range expansions (Parmesan et al. 1999; Warren et al. 2001; Parmesan and Yohe 2003; Hickling et al. 2006) and increasing elevational limits on mountain ranges (Green and Pickering 2002). Range contractions at southern range edges and lower elevational limits are also starting to be reported (Lesica and 
McCune 2004; Shoo et al. 2005; Franco et al. 2006). These changes may have dramatic consequences for biodiversity in the future. While mobile habitat generalists may expand their range northwards, the prospects for less mobile habitat specialists are generally less favourable. On the one hand, specialists may lose suitable habitat at the warmer end of their range while, on the other hand, colonization of newly suitable habitat northwards may fail because of the increasing fragmentation of the modern, man-made landscape (Warren et al. 2001). For some species, suitable climate ranges may even vanish altogether (Ohlemüller et al. 2008; Settele et al. 2008).

In the face of these changes, there is an urgent need to gain an understanding of the impact of climate change on population trends and range shifts in a wide range of species. An increasing number of studies attempt to predict potentially suitable future ranges by using climate envelopes that explain current range limits exclusively on the basis of climatic factors (Huntley et al. 2004; Heikkinen et al. 2006; Settele et al. 2008; Vos et al. 2008). Models combining climate envelopes and expected climate scenarios generate forecasts of suitable future ranges. This straightforward approach, however, may be an oversimplification of the true climate-determined impact. Indeed, the power of climate envelopes to predict future ranges has been seriously questioned in recent studies (Heikkinen et al. 2006; Beale et al. 2008; Schweiger et al. 2008; Nogués-Bravo 2009). In particular, in constructing climate envelopes, the importance of non-climate factors cannot be separated from true climate factors. Moreover, the underlying mechanisms affecting population dynamics are still insufficiently understood to obtain insight in the value of climate envelope models (Shoo et al. 2005; Huntley et al. 2010).

Recent studies have emphasized the significance of factors interacting with climate change that hamper the prediction of range shifts (Menéndez et al. 2007; Schweiger et al. 2008; Titeux et al. 2009; Heikkinen et al. 2010). Thus, neglecting dispersal may lead to a poor performance of bioclimatic models (Mitikka et al. 2008) as habitat fragmentation may prevent the colonization of newly suitable areas (Warren et al. 2001; Piessens et al. 2009; Willis et al. 2009). In contrast, selection for increased mobility may overcome dispersal limitation to some extent, and local adaptation may mitigate certain effects of climate change (Thomas et al. 2001; Visser 2008; Ashton et al. 2009). Further complexity arises because the micro- and macroclimate are only weakly related (see Stoutjesdijk and Barkman 1992; Kennedy 1997); hence, macroclimatic warming may not result in warmer microclimates. Thus, because ectotherms strongly depend on microclimatic conditions, it has been suggested that the advancing onset of plant growth would cause a cooling of larval microhabitats in the spring for grassland butterflies in temperate Europe (WallisDeVries and Van Swaay 2006). Clearly, there is a severe lack of understanding of the effects of current weather on population trends, which in turn undermines the correct appraisal of predictions emerging from climate envelope models. It therefore remains unclear to what extent populations will indeed shift along with their projected climatic niche and whether populations will actually remain stable in those parts of their range where the climatic niche is predicted to stay suitable.

In addition to gradual changes in temperature and rainfall patterns, extreme weather events, such as heat waves, prolonged drought or excessive rainfall, also need to be taken into consideration. These may prove to be important drivers of climate-related impacts on species populations (Ehrlich et al. 1980; Morecroft et al. 2002; Jentsch et al. 2008; Piessens et al. 2009). The impact of weather extremes may directly affect populations by increased mortality (Mercader and Scriber 2008) and reduced reproduction (Papaj et al. 2007) or indirectly by changes in host plant availability (Piessens et al. 2009) or changing rates of parasitism and predation (Dennis 1993; Menéndez et al. 2008; Parmesan et al. 2000).

In this article we propose an alternative approach to avoid some of the above-mentioned shortcomings of climate envelope models by focusing on the relation between population trends and climatic variables, including measures of extreme weather. We have specifically analyzed the impact of short-term climatic variation on annual changes in butterfly population trends. Thus, range shifts may eventually result from positive or negative impacts of climatic change on population trends in a given region. Butterflies are appropriate model organisms as ectothermy makes them sensitive to climatic variation and their short generation times quickly reflect changes at the population level. In addition, good monitoring data are available for butterflies. We used data collected within the framework of the Dutch Butterfly Monitoring Scheme for 40 species over a 15-year period and corresponding climate data. Four additional years were used for model validation. Future population trends were then predicted under a likely weather scenario for the end of the 21st century. A similar analysis was carried out earlier by Roy et al. (2001) for the UK, but our aim was to carry their approach further by emphasizing the weather experienced during successive developmental stages-rather than apply their straightforward analysis using monthly periods. Moreover, we investigated the significance of extreme weather events. To this end, we included extreme weather variables in the trend analysis and evaluated the impact of the extremely warm and dry summer of 2003 on species found in drought-susceptible habitats. Our general hypothesis was that temperature increases will generally lead to increasing butterfly populations 
in a temperate climate such as that of The Netherlands. However, milder winters are expected to have a negative impact (WallisDeVries and Van Swaay 2006), and climatic extremes are thought to be detrimental, especially to drought-susceptible species (Ehrlich et al. 1980; Stefanescu et al. 2004). At the same time, we expected to find that trends may be determined by factors quite unrelated to climate. We surmised that climate scenarios following our analysis may reveal significantly different predictions for the fate of butterflies towards the end of the 21 st century than those envisaged by climate envelope models.

\section{Materials and methods}

We examined butterfly abundance against the weather experienced during the life cycle from 1 year to the next. We distinguished both average and extreme temperatures as well as averages and extremes in precipitation. Multiple regression was applied to explain annual changes in population indices, using part of the dataset for validation.

\section{Monitoring data}

We obtained data on butterfly population trends over the period 1990-2008 from the Dutch Butterfly Monitoring Scheme. The data reflect butterfly numbers from weekly counts between 1 April and 30 September along permanent transects under suitable weather conditions (for more details on methods, see Pollard and Yates 1993). The number of transects increased from about 100 in 1990 to $>400$ since 2003. The transects are distributed over the whole country; imbalances in geographical distribution are corrected by a weighting procedure (Van Swaay et al. 2002). Trends were calculated using time series analysis with missing data, based on log-linear regression analysis (Van Swaay et al. 2002). For most species, the first flight period is used to calculate trends because this is known to be more accurate (Van Strien et al. 1997). However, the greater butterfly numbers from the second flight period are used for two scarce species (Aricia agestis and Lycaena tityrus) as well as for species hibernating as adults (Aglais urticae, Gonepteryx rhamni, Aglais io, Polygonia c-album), which often start flying earlier than 1 April after hibernation. Species counted at $<10$ locations or for $<15$ years were excluded, which restricted the number of species to 40 .

\section{Butterfly life history}

In order to give a biological meaning to weather variables, we chose seven stages in the life cycle of butterflies that are possibly affected by climate. These are, depending on the species, hibernation, spring larval period, spring pupation, first flight period, first active larval period in the summer, second flight period and second active larval period in the summer. With the exception of egg-hibernating species, the egg stage was not included because it is generally brief and strongly overlaps with flight and larval periods. The pupal stage was also not included-except for the spring pupation for which it is believed that weather events, such as late frost, might be relevant. Partial second and third generations were also not considered. Two species with flexible phenology had to be treated differently: for Issoria lathonia, the overlap between different generations is so strong that these were considered to be a single overall generation and for Pararge aegeria, we assumed the pupa to be the more common hibernation mode, although it may also overwinter in the larval stage.

The dates on the start and completion of various stages [see Electronic Supplementary Material (ESM) 1)] were derived from 10 and $90 \%$ values of recorded flight dates for the various species during the period 1980-2003 (Bos et al. 2006). Captive breeding experiments outdoors (Bink 1992) provided data on the duration of the egg, larval and pupal stages.

We estimated the start of the oviposition period to be one-third of the duration of the flight period (because females emerge later than males), augmented by the duration of egg maturation, i.e. the number of days required before an emerging female starts ovipositing. The end date for oviposition was calculated as the end of the flight period plus the duration of the egg stage until hatching. The start of the larval period was then calculated as the start of the oviposition period plus the duration of the egg stage until hatching; the end of the larval period was calculated as the end of the egg stage plus the duration of the larval period. A similar approach was followed for the starting dates of other periods in the life cycle. Only the hibernation period was set at a fixed date for all species, i.e. starting on 1 November and ending on 1 March.

Although we are aware of significant annual variation in butterfly phenology (e.g. Van Strien et al. 2008), we are confident that we obtained a robust estimate of the crucial periods. By using more than 20 years of data, we covered a broad range of year-to-year variation.

\section{Weather data}

Data on daily temperature and precipitation were obtained from the national meteorological station in De Bilt $\left(52.11^{\circ} \mathrm{N}, 5.18^{\circ} \mathrm{E}\right.$; http://www.knmi.nl). As the territory of Netherlands encompasses an area of $300 \times 200 \mathrm{~km}$, a single weather station is representative of the general weather pattern for the entire country.

In addition to average temperature and total precipitation, we distinguished five potentially important extreme 
weather events during the various stages of the butterfly's life cycle. These are heavy rain (days with $>20 \mathrm{~mm}$ of precipitation), heat (days with maximum temperature $>30.0^{\circ} \mathrm{C}$ ), late frost (days after 15 March with minimum temperature $<0.0^{\circ} \mathrm{C}$ ), warm spells during winter (days with mean temperature $>8^{\circ} \mathrm{C}$; after Dennis 1993) and drought. In contrast to the other extremes, which have clear definitions in meteorological terms, drought had to be newly defined. This was done in two ways: first, simply as a period (number of days) without precipitation; secondly, as a period with a precipitation deficit below the long-term $10 \%$ value of the daily cumulative precipitation deficit between 1 April and 1 October ( 5 and 50 percentile values were also tested but did not have added value). The first approach gives a continuous indication of drought more suitable for regression analysis, whereas the second only denotes extreme drought.

All extremes were defined as the number of days meeting the specified criteria during a given stage of the life cycle. Drought and heavy rain might have an impact on adult and larval stages because of desiccation of nectar and feeding plants and direct mortality, respectively. Heat was assumed to restrict flight activity. Late frost could cause mortality in late larval instars and pupae, especially in combination with high average temperatures that increase growth rates. Warm days during the winter could be especially detrimental to overwintering adults because of increased energy expenditure in a period without nectar resources to restore body reserves.

Regression models and validation

Stepwise multiple linear regression was applied to explain the variation in the logarithmic index value of butterfly abundance during the period 1990-2004; the index has a reference value of 2 in the year 1992. As explanatory variables we used the set of weather variables as well as a parameter for density dependence. The combination of weather variables and butterfly life stages generated a total of 20 variables for average weather and 22 variables for weather extremes. Clearly, not all variables applied to each species because of differences in life history, such as the number of generations per year and the developmental stage during hibernation. Weather variables of the current flight period and the whole preceding year were included in the regression. Possible density-dependent effects on the index were accounted for by including the index of the preceding year; the inclusion of data from more previous years was not expected to provide additional explanatory power, which is in line with the findings of Roy et al. (2001). We included quadratic terms for each variable to test for curvilinear effects.
A regression analysis with more explanatory variables than the number of observations, i.e. the years in the observation period, runs the risk of obtaining biologically meaningless spurious relations. As a precaution, therefore, we restricted the analysis to the two main explanatory variables with a threshold of $P<0.10$ for including a variable into the regression model. To validate this approach, we explored the effect of extending the maximum number of explanatory variables from two to four. In the regression analysis, we gave priority to variables for average weather over those for extreme weather, when both were of comparable significance. This ensures a more robust assessment of the significance of extreme events, as the two are often correlated.

We also carried out a validation of the results obtained in the regression by predicting the index values for the period 2005-2008 and comparing these with the observed values.

\section{Long-term predictions}

The regression models were used to predict long-term trends for butterfly abundance under one of the possible weather scenarios for the second half of the 21 st century. For species showing a significant dependence of the population index on the density in the preceding year, an initial index value was required, which we set at the baseline value of 2 .

We considered regionalized predictions for The Netherlands under the so-called A2-scenario for economic development (IPCC 2000; Van den Hurk et al. 2007). This scenario has been converted to daily weather events over a 30-year period (2071-2100) under the assumption that dayto-day variation will remain similar to the present variability. The average annual temperature in this scenario is expected to increase from $10^{\circ} \mathrm{C}$ in the period $1976-2005$ to $13.5^{\circ} \mathrm{C}$ in $2071-2100$. Annual precipitation is expected to increase from 816 to $885 \mathrm{~mm}$. Average temperatures under this scenario will increase in all months. Winters will become wetter with more periods of excessive rainfall. Overall precipitation in the summer will not change much, but short periods of heavy rainfall will be more frequent, together with prolonged periods of drought.

We were aware that extrapolation beyond the ranges of the modelling domain is hazardous because the model may not be valid under different circumstances. However, we deemed this step justifiable in the present case because there was still a $38 \%$ overlap between the average monthly temperatures under the climate scenario and the data used for building the predictive models; moreover, daily variability in temperatures is high, and the standard deviations of daily temperature values around monthly means still show a wide overlap between 1990-2003 and the scenario values for 2071-2100. 
Future trends in abundance from our regression analysis were compared with predicted changes in distribution based on climate envelopes (Settele et al. 2008) to obtain an indication of agreement and differences between the two approaches. To this effect, we interpreted projected range shifts at the regional scale of The Netherlands and neighbouring countries. Expansions in this region were interpreted as population increases, shrinking ranges as declines and no change as stability.

Effects of the extreme summer of 2003

The summer of 2003 has been used in earlier studies as an example of extreme weather that may occur more frequently in the future (Schär et al. 2004; Piessens et al. 2009). This summer was also extreme in The Netherlands. Mean temperature during the three summer months was $18.6^{\circ} \mathrm{C}$, compared to $16.7^{\circ} \mathrm{C}$ for the preceding 30 years, with a heat wave lasting for 2 weeks, including 7 days with maximum temperature exceeding $30^{\circ} \mathrm{C}$, which was double the annual long-term average. Precipitation was limited to $119 \mathrm{~mm}$ and sunshine peaked at $736 \mathrm{~h}$ against $202 \mathrm{~mm}$ and $591 \mathrm{~h}$, respectively, for the long-term average (http:// www.knmi.nl).

We expected that the combination of heat and drought would be more pronounced in nine habitat specialists from grasslands, heathlands and dunes (Hesperia comma, Pyrgus malvae, Ochlodes sylvanus, Maculinea alcon, Plebejus argus, Argynnis aglaja, Argynnis niobe, Hipparchia semele, $H$. statilinus) than in five grassland generalists (Thymelicus lineola, Anthocharis cardamines, Maniola jurtina, Aphantopus hyperanthus, Pyronia tithonus) or 25 miscellaneous species from a variety of habitats. Habitat specialists and generalists were restricted to species with a single generation per year, because these may be thought to be more susceptible to extreme events than species with multiple generations. All habitat specialists have a Red List status in The Netherlands (Bos et al. 2006). We compared the population index for these three groups in 2003 with its value in the preceding year and the two following years.

\section{Results}

Weather-based regression models

We obtained significant regression models for 39 of the 40 butterfly species, with more than $50 \%$ of explained variation in 28 species (Table 1, Fig. 1, ESM 2). Weather-independent density dependence of the index in the current year on its value in the preceding year was observed in 13 species, with positive density dependence recorded in 12 species. In addition to density dependence, effects from the previous year were generally not more frequent than effects from the current year. Average weather variables were more frequently included in the regression than extreme weather variables (8.5 vs. 3.7\%; Fisher's exact test, $P=0.0015)$, with a similar probability for positive or negative effects.

There was significant variation in the impact of seven different types of weather events (warm winters, late frost, heavy rain, drought, total rainfall and mean temperature; likelihood ratio test $P=0.006$ ), with the most frequent effects recorded for mean temperature and only a few significant effects of late frost and heat. Effects of temperature outside the winter period were more frequently positive than the effects of precipitation (63.3 vs. 31.0\%; Fisher's exact test $P=0.0191$ ). Drought was more successfully included in the regression models as the number of dry days than as a precipitation deficit: precipitation deficit was a more powerful explanatory variable in a minority of six of 15 significant cases, and it consistently resulted in an increased deviation in the validation, except for Hesperia comma.

The frequency of effects differed little between life stages. Weather effects during hibernation were significant in five species only and were always negative, which was still significantly more than its effects during other life stages (100 vs. 42\%; Fisher's exact test $P=0.0184$ ). Higher temperatures had more positive effects during the flight period on species hibernating as eggs or larvae, especially in the previous year, than on species hibernating as adults or pupae (40\% of 25 species vs. $7 \%$ of 15 species; Fisher's exact test $P=0.0302$ ); an optimum response to temperature was only apparent in Maniola jurtina (optimum temperature $19.2^{\circ} \mathrm{C}$ ). Species hibernating as pupae reacted more often positively to higher temperatures during the larval period in the preceding year than species hibernating as larvae (36\% of 11 species vs. $0 \%$ of 19 species; Fisher's exact test $P=0.012$ ). The four species hibernating as adults were only affected by weather in the spring flight period.

\section{Validation}

Validation of short-term trend predictions from the regression models was carried out with additional data from the years 2005-2008 (Figs. 1, 2; ESM 2). The average absolute deviation of the predicted index was $<15 \%$ of the observed index for 20 of the 39 species with a significant regression model (Table 1). Deviation in index values was not correlated with the $R^{2}$ value of the regression model $(r=+0.03$, $P=0.86)$. Species with a higher deviation in predictions tended to have a lower index of abundance $(r=-0.42$, $P=0.0086$; Fig. 2), but the inaccuracy was especially correlated with higher variability in the index $(r=+0.80$ with 


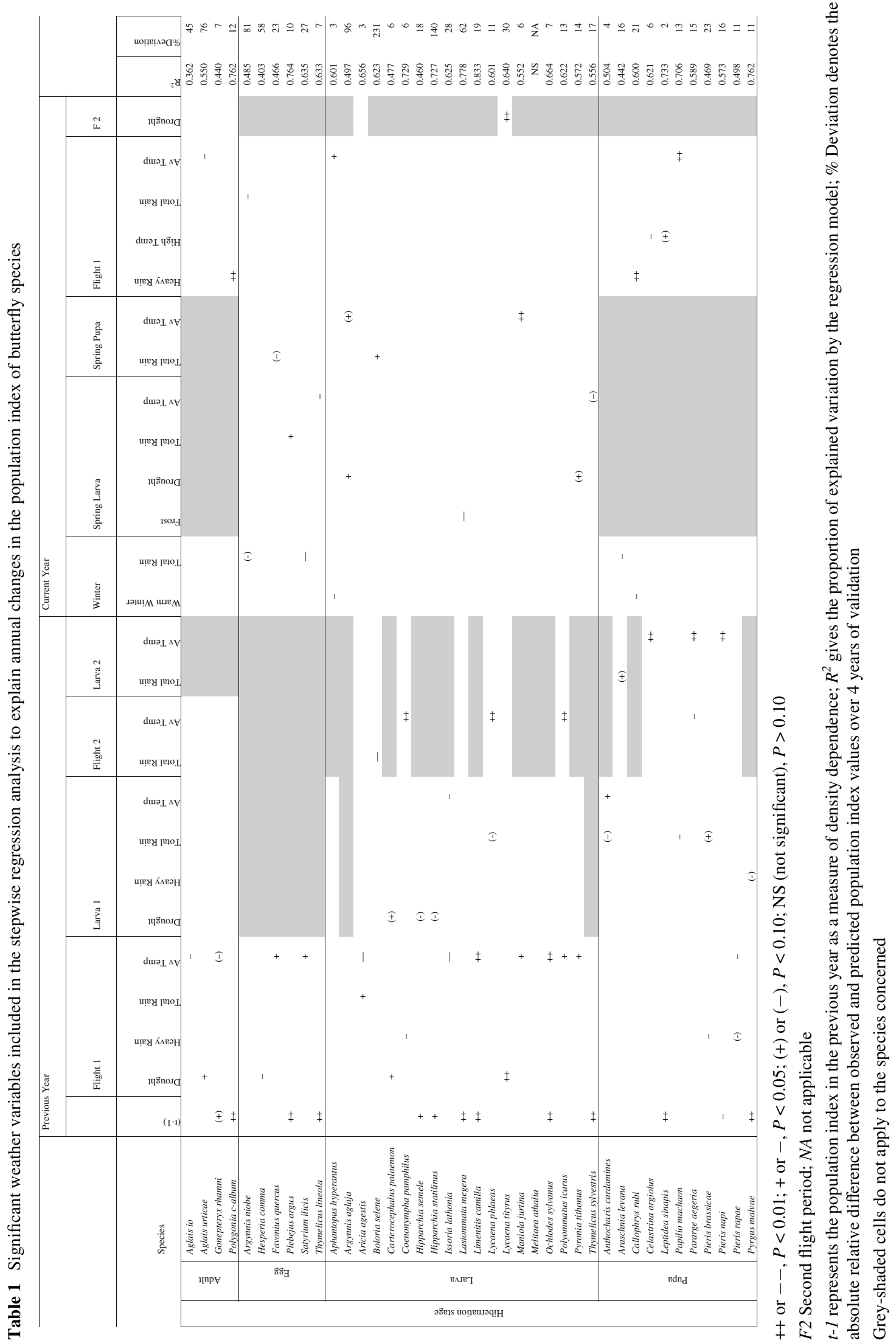



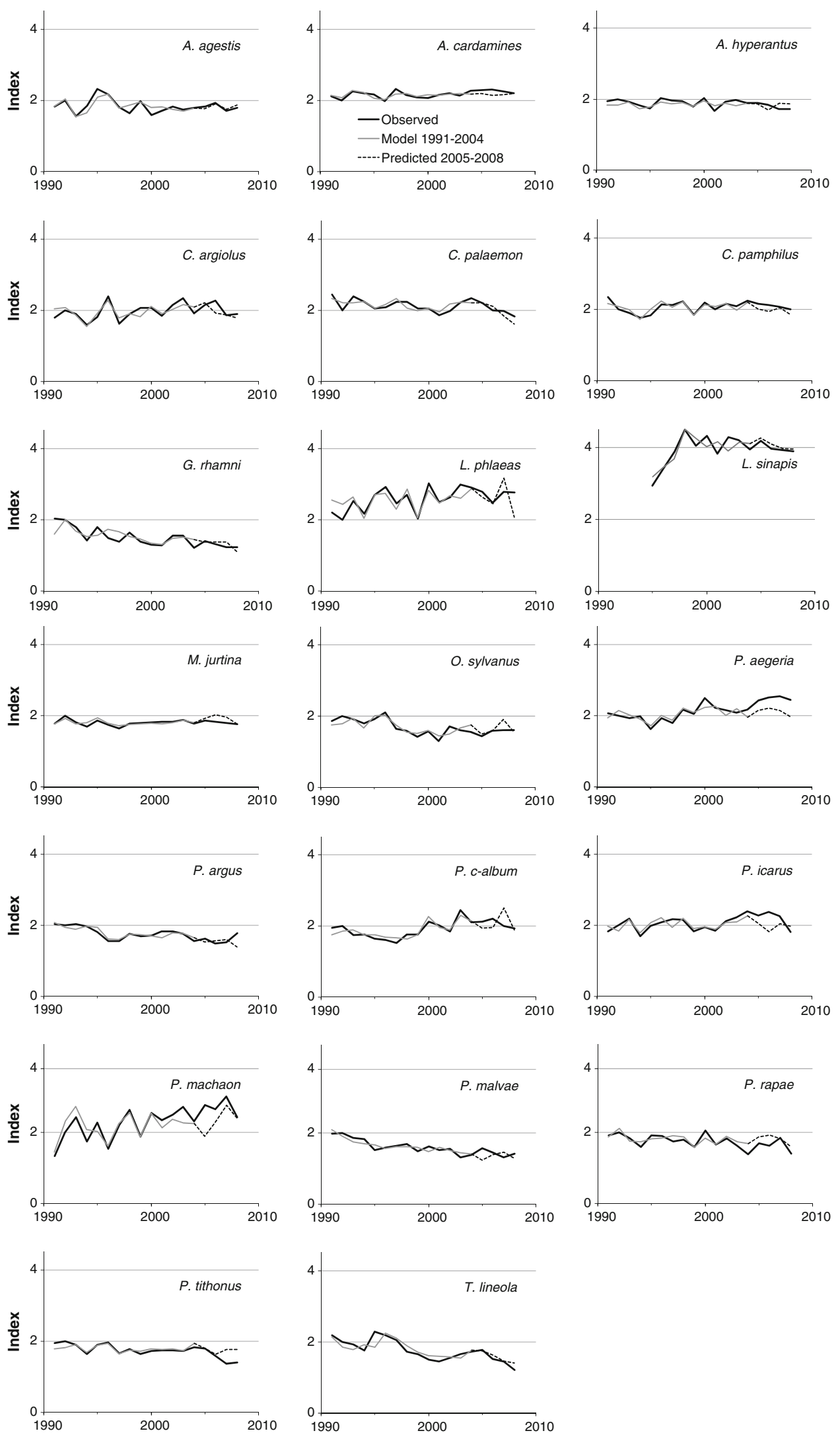

Fig. 1 Observed, modeled and predicted indices of butterfly abundance for 20 species with accurate predictions (deviation of predicted index $<15 \%$ on average) 


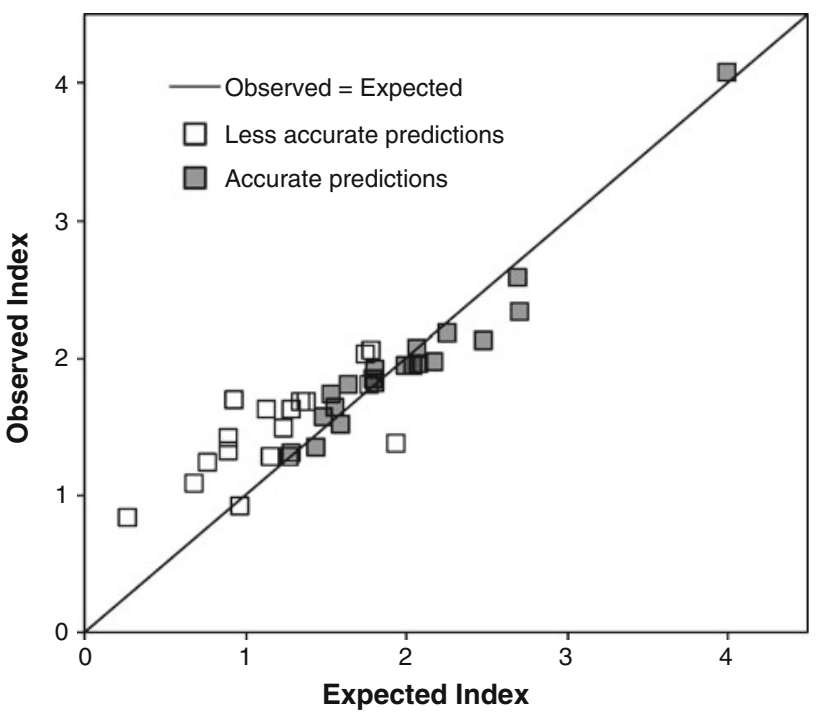

Fig. 2 Observed versus predicted indices of butterfly abundance for species with accurate predictions (filled squares) and less accurate predictions (open squares); deviation of predicted index $<15$ or $>15 \%$ on average, respectively

the coefficient of variation of indices between years; $P<0.0001)$.

We compared the performance of regression models using a maximum of two or four explanatory variables. Regression models with more than two significant explanatory variables were found for 28 species (out of the 39 with any significant regression model). Extending the number of variables resulted in an overall worsening of model predictions by $3.1 \%$ (SE 2.2). Consistent improvements in predictive power were only found for L. tityrus and L. megera (absolute deviation reduced by 14 and 18\%, respectively), but the remaining deviation in the predictions was still substantial (16 and 44\%, respectively).

Long-term predictions

Expected population trends under a climate scenario for the second half of the 21st century were calculated (Table 2). A comparison of long-term predictions and current trends against the baseline index value of 2 showed a good agreement between current and future trends for 27 species, worsening index values in only four species and improving index values in nine species. A comparison of our predictions with projected range shifts based on climate envelopes revealed much less agreement, with a significantly higher proportion of population decline under the predictions from our regression models (likelihood ratio test, $P<0.0001)$. At the regional scale of The Netherlands, the climate envelope projections anticipate more stability (27 species) and much less decline (5 species) than our predictions ( 9 species stable and 26 species in decline).

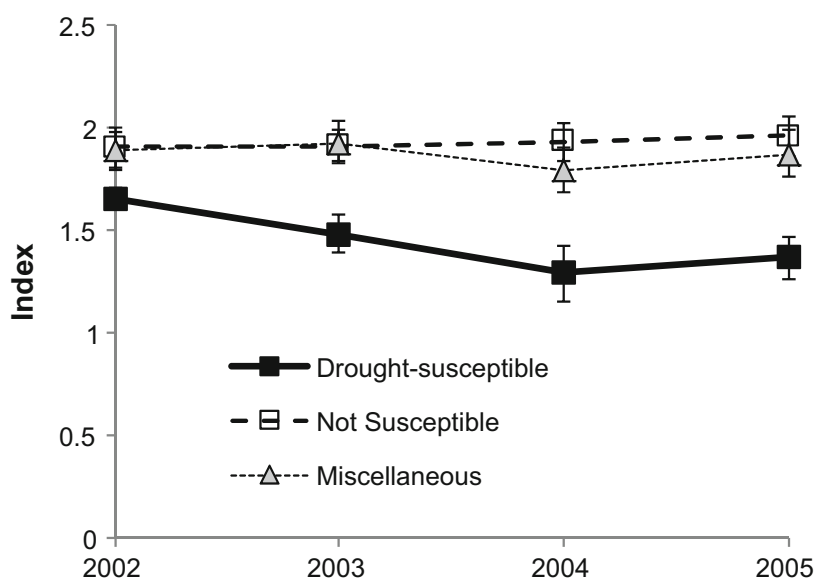

Fig. 3 Indices of butterfly abundance $( \pm S E)$ before, during and after the extreme summer of 2003 for three groups of species: drought-susceptible habitat specialists $(n=9)$, not susceptible habitat generalists $(n=5)$ and miscellaneous other species $(n=25)$

Impact of the extreme summer of 2003

Specialists from drought-susceptible habitats showed a significant decline in abundance from 2002 to 2004 (slope: $-0.182 \pm 0.051)$ in contrast to less susceptible habitat generalists that remained at a constant level (slope: $+0.016 \pm$ 0.069 ; difference $P=0.0388$ ). The population index of a miscellaneous group of other species also did not vary significantly (Fig. 3). All three groups showed a slight, though non-significant increase from 2004 to 2005 , indicating that the decline in drought-susceptible habitat specialists was linked with the events in the period 2003-2004. In the regression analysis, significant negative effects of drought on the population index were apparent for the three species from the driest habitats (Hesperia comma, Hipparchia semele, H. statilinus).

\section{Discussion}

Population trends, weather impact and life history

The aim of this study was to provide a more mechanistic basis by which to explain the effects of climate change on population trends in ectothermic invertebrates, such as butterflies. To this end, we focused on short-term effects of weather events during various stages of the life cycle. Our results show this approach has a good potential to achieve our aim. Significant impacts of weather were found for most species, and validation of the results showed that accurate predictions are possible in about half of the species we studied. Less accurate predictions were not linked to the degree of explained variation by the regression model; 
Table 2 Comparison between current trends in butterfly abundance, predicted trends in abundance for 2071-2100 according to the regression models from this study and predicted trend in the distribution for northwestern Europe according to the climate atlas by Settele et al. 2008 (BAMBU scenario for 2080)
NA, weather variables were not significant in the regression model

${ }^{a}$ Population trends reflect significant differences $(P<0.05)$ in comparison with the initial population index of 2 in 1992

b Climate atlas predictions reflect regional range shifts (increase $=$ expansion; decline $=$ shrinkage $)$

c Species are grouped according to overwintering stage

\begin{tabular}{llll}
\hline Species & Current trend & Trend prediction & Climate atlas \\
& $1990-2004^{\mathrm{a}}$ & $2071-2100^{\mathrm{a}}$ & prediction 2080 \\
\hline
\end{tabular}

Hibernation stage ${ }^{c}$

Adult

Aglais io

Aglais urticae

Gonepteryx rhamni

Polygonia c-album

Egg

Argynnis niobe

Hesperia comma

Favonius quercus

Plebejus argus

Satyrium ilicis

Thymelicus lineola

Larvae

Aphantopus hyperantus

Argynnis aglaja

Aricia agestis

Boloria selene

Carterocephalus palaemon

Coenonympha pamphilus

Hipparchia semele

Hipparchia statilinus

Issoria lathonia

Lasiommata megera

Limenitis camilla

Lycaena phlaeas

Lycaena tityrus

Maniola jurtina

Melitaea athalia

Ochlodes sylvanus

Polyommatus icarus

Pyronia tithonus

Thymelicus sylvestris

Pupae

Anthocharis cardamines

Araschnia levana

Callophrys rubi

Celastrina argiolus

Leptidea sinapis

Papilio machaon

Pararge aegeria

Pieris brassicae

Pieris napi

Pieris rapae

Pyrgus malvae
Decline

Decline

Decline

Increase

Decline

Decline

Decline

Decline

Decline

Decline

Stable

Decline

Decline

Decline

Stable

Increase

Decline

Decline

Decline

Decline

Decline

Stable

Decline

Stable

Decline

Decline

Increase

Decline

Decline

Stable

Stable

Stable

Stable

Increase

Increase

Increase

Decline

Stable

Decline

Decline
Decline

Decline

Decline

Stable

Decline

Decline

Increase

Decline

Decline

Decline

Decline

Decline

Decline

Decline

Stable

Increase

Decline

Increase

Decline

Stable

Increase

Increase

Decline

Increase

NA

Increase

Increase

Decline

Decline

Increase

Decline

Decline

Increase

Increase

Increase

Increase

Decline

Increase

Decline

Decline
Stable

Decline

Stable

Stable

Stable

Stable

Stable

Stable

Stable

Stable

Decline

Decline

Stable

Decline

Stable

Stable

Stable

Increase

Increase

Stable

Increase

Stable

Increase

Stable

Increase

Stable

Stable

Increase

Stable

Decline

Stable

Stable

Stable

Increase

Increase

Stable

Stable

Stable

Stable

Stable 
rather, they were associated with species displaying a high variability in butterfly numbers, such as Aglais urticae.

Focusing on the susceptibility of different life stages to weather conditions appears a fruitful approach, as shown by Hellmann et al. (2008) in population studies of two butterfly species supported by controlled experiments. However, this approach has its limitations when applied to field data, as in our study. In particular, only those stages with a longer duration can be assessed with any reliability. Thus, egg and pupal stages outside the hibernation period are too short to be meaningfully included in our analysis. Indeed, few significant results were found for the spring pupal period that we did include. The estimates for flight, larval and hibernation periods, however, do appear to be realistic. A comparison of observed against estimated flight periods showed that observed flight periods usually fell entirely within the estimated limits, with an overestimation of the length of the flight period by 11.8 days ( \pm 6.7 standard deviation) on average, with an average flight period lasting 32 days. Refining the methods by deriving the phenology from observed flight dates might be feasible (see Van Strien et al. 2008), but would probably not lead to more accuracy because parameters for other life stages would also need to be adapted by an unknown amount. Our broad definition of life stage phenology does appear to offer a robust and still sufficiently representative timing of at least the longer stages during the life cycle.

We found significant effects of weather on the abundance of all but two species. The most frequent effects were found for temperature; in contrast, effects of heat and late frost were rare. Temperature effects on abundance were mostly positive outside the winter period, with warmer flight periods in the previous year often being more beneficial for species hibernating as eggs or larvae and warm larval periods before hibernation benefitting species hibernating as pupae. Such effects may be expected for ectothermic species in a temperate climate (Dennis 1993; Roy et al. 2001; Dennis and Sparks 2007). Species overwintering as adults were mainly affected by weather conditions during the spring flight period, with a negative response to temperature in three of four species.

Negative effects on butterfly abundance were found for precipitation and mild or rainy winters. The negative effects of winter conditions are in line with long-term observations in British Lepidoptera (Dennis and Sparks 2007) but were found in just five species in our study. Together with positive effects of drought and low temperatures during the spring larval period in four species, this finding provides some support for the microclimatic cooling hypothesis (WallisDeVries and Van Swaay 2006), which predicts that butterflies with larval development during the spring will suffer from cooler microclimates under climatic warming as a result of the plant growing season advancing to a greater extent than the advance in larval development. Still, the support concerned fewer species than expected. For Plebejus argus, for example, the negative effect of desiccation may override possible positive effects on microclimate.

Another important finding was the substantial impact of non-climatic factors. In addition to the impact of weather factors, we found positive density dependence in 12 species and negative density dependence in a single species, Pieris napi. Negative density dependence points to population regulation around a certain level of dynamic equilibrium, as expected from classic population ecology (Stiling 1988), with negative feedbacks from parasitoids and other regulatory mechanisms on overpopulation. Positive density dependence, however, indicates positive feedbacks and persistent trends. In this case, positive density dependence was found in two increasing species and ten decreasing species. The trends in these species are probably linked to long-term changes in land use leading to, respectively, increasing habitat suitability for increasers and the loss and fragmentation of habitats for decreasers (Warren et al. 2001; Opdam and Wasscher 2004; Pöyry et al. 2008). Thus, our results underline the importance of not overestimating climatic factors as drivers of population trends, especially in declining species.

Impact of average and extreme weather

In our study, average weather (i.e. average temperature and total precipitation) was found to have twofold more significant effects than variables reflecting extreme weather, such as heat, drought or late frost. The robustness of these weather extreme estimates was confirmed by applying different thresholds for extreme weather-drought in particular. The procedure to give priority to average weather variables for entry in the regression models (see "Materials and methods") was only applied in five species and thus only affected a minor proportion (8\%) of significant weather events. The statistical problem of dealing with extremes in regression analysis appears to be a greater obstacle, as shown by the poor performance of the precipitation deficit during validation. Still, the importance of weather extremes for butterflies noted by Pollard and Yates (1993) and Roy et al. (2001), for example, does become clear from our analysis of the impact of the summer of 2003, which revealed a significant decline of specialist species in drought-susceptible habitats, such as dunes and heathlands. The reproduction of these species within their habitat during this drought was probably seriously impaired by the desiccation of both nectar and host plants. Evidence for increased emigration in response to the drought was found for the heathland specialist Hipparchia semele in distribution records, showing a significant higher incidence of H. semele outside its habitat in 2003 than in 2002 and 2004 
(WallisDeVries, unpublished data). Many of these butterflies were even observed nectaring in urban areas, but reproduction outside heathlands or dunes was probably minimal through the lack of a suitable larval habitat. In contrast, the drought had no significant effect on generalist species, which could also rely on habitats that were less affected by the drought.

Our analysis shows that while regression analyses may reveal overall relations between weather patterns and butterfly abundance, a focus on separate events may be necessary to gain insight into the impact of weather extremes. Experimental work under controlled conditions, as carried out by Hellmann et al. (2008), is required to improve the biological basis to define extreme events in relation to the life history and ecology of individual species or groups of species.

\section{Long-term predictions}

Our findings contribute towards a more mechanistic basis for assessing the effects of climate change on butterflies. The prediction of long-term trends for the second half of the 21st century suggest an overall increase of butterfly abundance under a scenario of climatic warming, with more species increasing than declining. This is not surprising for ectothermic species at the northwestern limit of their range and in line with observed changes in other studies (Dennis 1993; Thomas et al. 1999; Roy et al. 2001). However, weather extremes and climate-independent factors may override the overall positive effect of climate change. In particular, changes in land use may well prevent the potential increase of habitat specialists with poor dispersal capacity. Extreme weather events, such as the drought that occurred in the summer of 2003, may cause further declines.

The range shifts predicted by climate envelope models may be interpreted as population increases under range expansion and decreases under range contraction. On the regional scale of The Netherlands, this interpretation of predicted range shifts by Settele et al. (2008) appears to substantially overestimate the positive effects of climate change in comparison with our analysis. This difference is undoubtedly caused in part by our inclusion of climateindependent factors in the form of density dependence, but possibly also by our more mechanistic approach to explain population trends as a function of weather. Thus, even when species with significant density dependence are discarded, we predict the populations of 12 other species to show climate-related declines even though their climate envelope is predicted to remain suitable. Settele et al. (2008) have already pointed out many of the possible shortcomings of predictions based on climate envelope models, limited dispersal capacity in particular. Indeed, Heikkinen et al. (2010) have attempted to overcome some of these shortcomings. Still, our results do emphasize that climate envelope models may generate overoptimistic scenarios under climate change for species in the central or northern part of their ranges. In these regions, climate envelope models generally predict range expansions or changes within the limits of a species' bioclimatic niche. However, our results show that population trends are often incompatible with these expectations. Such a discrepancy between trends in population size and distribution area has been pointed out by Shoo et al. (2005). Consequently, the challenge is to develop more accurate mechanistic population models in relation to climate change.

Acknowledgments We thank the many volunteers who contribute to the Dutch Butterfly Monitoring Scheme, a joint project of Dutch Butterfly Conservation and Statistics Netherlands (CBS), financed by the Dutch Ministry of Agriculture, Nature and Food Quality. We greatly appreciate the stimulating discussions with many colleagues, in particular Chris Van Swaay, Arco Van Strien and Claire Vos. The comments by Claire Hengeveld and two anonymous reviewers substantially improved the quality of the manuscript.

Open Access This article is distributed under the terms of the Creative Commons Attribution Noncommercial License which permits any noncommercial use, distribution, and reproduction in any medium, provided the original author(s) and source are credited.

\section{References}

Ashton S, Gutiérrez D, Wilson RJ (2009) Effects of temperature and elevation on habitat use by a rare mountain butterfly: implications for species responses to climate change. Ecol Entomol $34: 437-446$

Beale CM, Lennon JJ, Gimona A (2008) Opening the climate envelope reveals no macroscale associations with climate in European birds. Proc Natl Acad Sci USA105:14908-14912. doi:10.1073/ pnas.0803506105

Bink FA (1992) Ecologische Atlas van de Dagvlinders van Noordwest-Europa. Schuyt, Haarlem

Bos FG, Bosveld MA, Groenendijk DG, Van Swaay CAM, Wynhoff I (2006) De Dagvlinders van Nederland-Verspreiding en Bescherming. Nederlandse Fauna 7. Nationaal Natuurhistorisch Museum Naturalis/KNNV Uitgeverij/EIS-Nederland, Leiden

Dennis RLH (1993) Butterflies and climate change. Manchester University Press, Manchester

Dennis RLH, Sparks TH (2007) Climate signals are reflected in an 89 year series of British Lepidoptera records. Eur J Entomol 104:763-767

Ehrlich PR, Murphy DD, Singer MC, White RR, Brown IL, Sherwood C (1980) Extinction, reduction, stability, and increase: the responses of checkerspot butterfly Euphydryas populations to the California drought. Oecologia 46:101-105

Franco AMA, Hill JK, Kitschke C, Collingham YC, Roy DB, Fox R, Huntley B, Thomas CD (2006) Impacts of climate warming and habitat loss on extinctions at species' low-latitude range boundaries. Global Change Biol 12:1545-1553

Green K, Pickering CM (2002) A scenario for mammal and bird diversity in the Australian snowy mountains in relation to climate change. In: Koerner C, Spehn EM (eds) Mountain biodiversity: a global assessment. Parthenon Publishing, London, pp 241-249 
Heikkinen RK, Luoto M, Araújo MB, Virkkala R, Thuiller W, Sykes MT (2006) Methods and uncertainties in bioclimatic envelope modelling under climate change. Progress Physical Geogr 30:751-777

Heikkinen RK, Luoto M, Leikola N, Pöyry J, Settele J, Kudrna O, Marmion M, Fronzek S, Thuiller W (2010) Assessing the vulnerability of European butterflies to climate change using multiple criteria. Biodivers Conserv 19:695-723. doi:10.1007/s10531009-9728- $\mathrm{x}$

Hellmann JJ, Pelini SL, Prior K, Dzurisin JDK (2008) The abundance and local adaptation of contrasting butterflies species at the edge of their geographic range. Oecologia 157:583-592

Hickling R, Roy DB, Hill JK, Fox R, Thomas CD (2006) The distributions of a wide range of taxonomic groups are expanding polewards. Global Change Biol 12:450-455. doi:10.1111/j.13652486.2006.01116.x

Huntley B, Green RE, Collingham YC, Hill JK, Willis SG, Bartlein PJ, Cramer W, Hagemeijer WJM, Thomas CJ (2004) The performance of models relating species' geographical distributions to climate is independent of trophic level. Ecol Lett 7:417-426

Huntley B, Barnard P, Altwegg R, Chambers L, Coetzee BWT, Gibson L, Hockey PAR, Hole DG, Midgley GF, Underhill LG, Willis SG (2010) Beyond bioclimatic envelopes: dynamic species' range and abundance modelling in the context of climatic change. Ecography 33:1-6. doi:10.1111/j.1600-0587.2009.06023.x

IPPC (Intergovernmental Panel on Climate Change) (2000) Emissions scenarios. Special report IPCC Working Group III. Cambridge University Press, Cambridge

Jentsch A, Kreyling J, Boettcher-Treschkow J, Beierkuhnlein C (2008) Beyond gradual warming: extreme weather events alter flower phenology of European grassland and heath species. Global Change Biol 15:549-837. doi:10.1111/j.1365-2486.2008.01 690.x

Kennedy AD (1997) Bridging the gap between general circulation model (GCM) output and biological microenvironments. Int J Biometeorol 40:119-122

Lesica P, McCune B (2004) Decline of arctic-alpine plants at the southern margin of their range following a decade of climatic warming. J Veg Sci 15:679-690. doi:10.1658/1100-9233(2004) 015[0679:DOAPAT]2.0.CO;2

Menéndez R, González-Megías A, Collingham Y, Fox R, Roy DB, Thomas CD (2007) Direct and indirect effects of climate and habitat factors on butterfly diversity. Ecology 88:605-611

Menéndez R, Gonzalez-Megias A, Lewis OT, Shaw MR, Thomas CD (2008) Escape from natural enemies during climate-driven range expansion: a case study. Ecol Entomol 33:413-421

Mercader RJ, Scriber JM (2008) Asymmetrical thermal constraints on the parapatric species boundaries of two widespread generalist butterflies. Ecol Entomol 33:537-545

Mitikka V, Heikkinen RK, Luoto M, Araujo MB, Saarinen K, Pöyry J, Fronzek S (2008) Predicting range expansion of the map butterfly in Northern Europe using bioclimatic models. Biodiv Conserv 17:623-641

Morecroft MD, Bealey CE, Howells E, Rennie S, Woiwod IP (2002) Effects of drought on contrasting insect and plant species in the UK in the mid-1990 s. Global Ecol Biogeogr 11:7-22

Nogués-Bravo D (2009) Predicting the past distribution of species' climatic niches. Global Ecol Biogeogr 18:521

Ohlemüller R, Anderson BJ, Araújo MB, Butchart SHM, Kudrna O, Ridgely RS, Thomas CD (2008) The coincidence of climatic and species rarity: high risk to small-range species from climate change. Biol Lett 4:568-572

Opdam P, Wasscher D (2004) Climate change meets habitat fragmentation: linking landscape and biogeographical scale levels in research and conservation. Biol Conserv 117:285-297. doi: 10.1016/j.biocon.2003.12.008
Papaj DR, Mallory HS, Heinz CA (2007) Extreme weather change and the dynamics of oviposition behavior in the pipevine swallowtail, Battus philenor. Oecologia 152:365-375

Parmesan C, Yohe G (2003) A globally coherent fingerprint of climate change impacts across natural systems. Nature 421:37-42. doi: 10.1038 /nature 01286

Parmesan C, Ryrholm N, Stefanescu C, Hill JK, Thomas CD, Descimon H, Huntley B, Kaila L, Kullberg J, Tammaru T, Tennent WJ, Thomas JA, Warren M (1999) Poleward shifts in geographical ranges of butterfly species associated with regional warming. Nature 399:579-583

Parmesan C, Root TL, Willig M (2000) Impacts of extreme weather and climate on terrestrial biota. Bull Am Meteorol Soc 81:443450

Piessens K, Adriaens D, Jacquemyn H, Honnay O (2009) Synergistic effects of an extreme weather and habitat fragmentation on a specialist herbivore. Oecologia 159:117-126

Pollard E, Yates TJ (1993) Monitoring butterflies for ecology and conservation. Chapman and Hall, London

Pöyry J, Luoto M, Heikkinen RK, Saarinen K (2008) Species traits are associated with the quality of bioclimatic models. Global Ecol Biogeogr 3:403-414

Roy DB, Rothery P, Moss D, Pollard E, Thomas JA (2001) Butterfly numbers and weather: predicting historical trends in abundance and the future effects of climate change. J Animal Ecol 70:201217

Schär C, Vidale P-L, Luethi D, Frei C, Haeberli C, Liniger MA, Appenzeiler C (2004) The role of increasing temperature variability in European summer heatwaves. Nature 427:332-336

Schweiger O, Settele J, Kudrna O, Klotz S, Kühn I (2008) Climate change can cause spatial mismatch of trophically interacting species. Ecology 89:3472-3479

Settele J, Kudrna O, Harpke A, Kühn I, Van Swaay C, Verovnik R, Warren M, Wiemers M, Hanspach J, Hickler T, Kühn E, Van Halder I, Veling K, Vliegenthart A, Wynhoff I, Schweiger O (2008) Climatic risk atlas of European butterflies. Pensoft, Moscow

Shoo LP, Williams SE, Hero J-M (2005) Potential decoupling of trends in distribution area and population size of species with climate change. Global Change Biol 11:1469-1476

Stefanescu C, Herrando S, Paramo F (2004) Butterfly species richness in the north-west mediterranean basin: the role of natural and human-induced factors. J Biogeogr 31:905-915

Stiling P (1988) Density-dependent processes and key factors in insect populations. J Animal Ecol 57:581-593

Stoutjesdijk P, Barkman JJ (1992) Microclimate, vegetation and fauna. Opulus Press, Sweden

Thomas JA, Rose RJ, Clarke RT, Thomas CD, Webb NR (1999) Intraspecific variation in habitat availability among ectothermic animals near their climatic limits and their centres of range. Funct Ecol 13:55-64

Thomas CD, Bodsworth EJ, Wilson RJ, Simmons AD, Davies ZG, Musche M, Conradt L (2001) Ecological and evolutionary processes at expanding range margins. Nature 411:577-581

Titeux N, Maes D, Marmion M, Luoto M, Heikkinen RK (2009) Inclusion of soil data improves the performance of bioclimatic envelope models for insect species distributions in temperate Europe. J Biogeogr 36:1459-1473. doi:10.1111/j.1365-2699.2009.020 88.x

Van den Hurk BJJM, Klein Tank AMG, Lenderink G, Van Ulden A, Van Oldenborgh GJ, Katsman C, Van den Brink H, Keller F, Bessembinder J, Burgers G, Komen G, Hazeleger W, Drijfhout S (2007) New climate change scenarios for The Netherlands. Water Sci Technol 56:27-33. doi:10.2166/wst.2007.533

Van Strien AJ, Van De Pavert R, Moss D, Yates TJ, Van Swaay CAM, Vos P (1997) The statistical power of two butterfly monitoring schemes to detect trends. J Appl Ecol 34:817-828 
Van Strien AJ, Plantenga WF, Soldaat LL, van Swaay CA, WallisDevries MF (2008) Bias in phenology assessments based on first appearance data of butterflies. Oecologia 156:227-235

Van Swaay CAM, Plate CL, Van Strien A (2002) Monitoring butterflies in The Netherlands: how to get unbiased indices. Proc Exper Appl Entomol NEV Amsterdam 13:21-27

Visser ME (2008) Keeping up with a warming world; assessing the rate of adaptation to climate change. Proc R Soc Lond B 275:649-659

Vos CC, Berry P, Opdam P, Baveco H, Nijhof B, O'Hanley J, Bell C, Kuipers H (2008) Adapting landscapes to climate change: identifying climate proof ecosystem networks and priority adaptation zones. J Appl Ecol 45:1722-1731
WallisDeVries MF, Van Swaay CAM (2006) Global warming and excess nitrogen may induce butterfly decline by microclimatic cooling. Global Change Biol 12:1620-1626

Warren MS, Hill JK, Thomas JA, Asher J, Fox R, Huntley B, Roy DB, Telfer MG, Jeffcoate S, Harding P, Jeffcoate G, Willis SG, Greatorex-Davies JN, Moss D, Thomas CD (2001) Rapid responses of British butterflies to opposing forces of climate and habitat change. Nature 414:65-69

Willis SG, Hill JK, Thomas CD, Roy DB, Fox R, Blakeley DS, Huntley B (2009) Assisted colonisation in a changing climate: a test-study using two UK butterflies. Conserv Lett 2:45-51 